\title{
социология
}

DOI: $10.17805 / g g z .2017 .2 .5$

\section{Проблема осознания экологической угрозы \\ в России}

\author{
Д. А. ТИХОМИРОВ, И. А. КИСТКИНА \\ РОССИЙСКИЙ ЭКОНОМИЧЕСКИЙ УНИВЕРСИТЕТ ИМ. Г. В. ПЛЕХАНОВА
}

Данная статья посвящена проблеме экологии в России. В ней поднимается вопрос об осознании властью и населением экологической угрозы. Показывается состояние и динамика общественного мнения по проблеме окружающей среды. На основе анализа экологического сознания и поведения делается вывод о низкой степени осознанности населением экологической угрозы. Формулируются рекомендации по изменению экологического сознания россиян.

Ключевые слова: экология; экологический кризис; экологическое сознание; экологическое поведение

\section{The problem of awareness of environmental threats in Russia}

\author{
D. A. TIKHOMIROV, I. A. KISTKINA \\ PLEKHANOV RUSSIAN UNIVERSITY OF ECONOMICS
}

This article deals with the problem of ecology in Russia. It raises the question about the awareness of authorities and population and environmental threats. Shows the status and the dynamics of public opinion on the issue of the environment. Based on the analysis of ecological consciousness and behavior, the conclusion about the low degree of awareness of population and environmental threats. Formulate recommendations for changes in the environmental consciousness of Russians.

Keywords: ecology; environmental crisis; ecological consciousness; ecological behavior

Экология становится одной из ключевых проблем в современном мире, от решения которой будет зависеть будущее человечества. Чрезвычайно сильное антропогенное воздействие на природу нарушает баланс в системе «человек-природа», создавая серьезные риски социальной устойчивости. Вполне гармоничные отношения в этой системе существовали на протяжении тысячелетий. Однако все изменилось с развитием технологий и формированием капиталистической модели экономики. Человек не только подчинил себе природу, но и изменил к ней отношение. Природа, по меткому выражению И. С. Тургенева, перестала быть храмом, став лишь мастерской, в которой человек - полновластный хозяин. Хищническое отношение к природе характеризует этого хозяина как нерадивого и недальновидного. Это проявляется в истощении природных ресурсов, загрязнении окружающей среды, изменении климата. Однако все имеет свой предел, в том числе и социальное давление на природу, которое особенно сильно проявляется в мегаполисах, в том числе и российской столице. Приблизилось ли человечество вплотную к этому пределу или у нас есть еще достаточно времени до 
наступления точки невозврата? Точно ответить на әтот вопрос довольно сложно, но, в любом случае, менять социальное поведение индивидов необходимо безотлагательно. Однако для этого необходимо осознание развертывания экологической проблемы и ее социальных последствий всеми заинтересованными сторонами: властью, бизнесом и населением. Выявлению степени осознанности экологической угрозы в российском обществе и посвящена данная статья.

Национальный лидер регулярно артикулирует проблему әкологии не только в своих публичных выступлениях, посланиях Федеральному Собранию РФ, но и в конкретных принятых им решениях и экологических акциях, направленных на защиту природы. Процитируем выдержки из выступления В. В. Путина на заседании Государственного совета по вопросу «Об экологическом развитии Российской Федерации в интересах будущих поколений», который состоялся в канун 2017 г., объявленного Президентом страны Годом экологии. «По ряду направлений нагрузка на природу достигла критических значений. В итоге ежегодный экономический ущерб доходит до 6 процентов ВВП, а с учетом последствий для здоровья людей - и до 15 процентов... Половина городского населения жив ет в условиях высокого уровня загрязнения воздуха. Вклад автотранспорта: и личного, и общественного - составляет от 50 до 90 процентов. Значительная часть поверхностных вод оценивается сегодня, как «грязные» и «экстремально грязные». Семь процентов жителей не обеспечены качественной питьевой водой. Практически во всех регионах сохраняется тенденция к ухудшению состояния почв и земель. Если мы и дальше будем обходиться полумерами и ссылаться на более важные задачи, то к 2050 году выбросы загрязняющих веществ и парниковых газов достигнут критического предела, а это значит, что будущим поколениям мы оставим среду, непригодную для жизни. Поэтому необходимо как минимум в два раза сократить загрязнения и выбросы» (Заседание..., 2016: Электронный ресурс). Таким образом, Президент России В. В. Путин не только осознает экологическую угрозу, нависшую над страной, но и принимает решения по ее устранению, задавая вектор развития экологической политики.

Но что делается конкретно на местах? Ждать социально ответственного экологического поведения от бизнеса в рамках рыночной экономики, по меньшей мере, наивно. Подтолкнуть бизнес изменить отношение к окружающей среде должны как органы власти, посредством установления более строгих әкологических нормативов, так и сами индивиды, посредством более избирательного в экологическом плане потребительского поведения. В идеале, общественное мнение и социальное поведение индивидов должны влиять на то, чтобы бизнесу было невыгодно загрязнять окружающую среду. Однако не все так просто, поскольку решение экологической проблемы является чрезвычайно затратным мероприятием, которое в полной мере не могут осуществить и наиболее развитые в экономическом плане страны. Соответственно, решая проблемы экологии, нельзя пренебрегать интересами экономики, конкретных предприятий и их работников. Но двигаться в экологическом направлении необходимо, иначе мрачные сценарии футурологов о разрушении экосистемы и катастрофических последствий этого в обозримом будущем воплотятся в жизнь.

Каково же отношение россиян к экологии? Проблема экологии стала артикулироваться в стране совсем недавно, в середине первой декады XXI века. И это не случайно, поскольку интенсивный экономический рост начала третьего тысячелетия привел к значительному (по сравнению с последним десятилетием XX века) повышению уровня жизни российского населения, в орбиту интересов которого вошли различные ас- 
пекты, касающиеся качества жизни, включая и экологию, находившиеся до этого в тени экономического кризиса. Опрос ВЦИОМ 2006 г. высветил изменение общественного мнения к проблеме экологии, которая стала рассматриваться как один из основных факторов неблагополучия. Загрязнение окружающей среды оказалось на четвертом место в иерархии проблем, представляющих наибольшую угрозу для жизни людей в России. Более опасными, чем плохая экологическая обстановка, казались только наркомания, алкоголизм и теракты (Экологическое..., 2006: Электронный ресурс). В 2006 г. большинство (57\%) россиян характеризовали экологическую обстановку в месте своего проживания как неблагополучную, из них 10\% указали, что ситуация очень плохая, близка к катастрофической. Противоположного мнения придерживались $41 \%$ респондентов, из них $12 \%$ считали ситуацию с экологией в целом благополучной. В 2013 г. восприятие экологической ситуации практически не изменилось: 56\% оценивали ее негативно (в т. ч. 9\% крайне негативно), а 41\% позитивно (но только $5 \%$ считают ее благополучной, а не 12\%, как это было в 2006 г.) (Россияне..., 2013: Электронный ресурс). Представленные данные дают основание заключить, что проблема экологии не только вошла в фокус общественного мнения, но и закрепилась в нем.

Вхождение проблемы экологии в публичный дискурс, активное ее муссирование СМИ, привело к тому, что большинство россиян стали негативно оценивать экологическую ситуацию, отмечая ее постоянное ухудшение. По данным исследований ВЦИОМ, если в 2009 г. $41 \%$ респондентов отметили ухудшение экологической обстановки в месте их проживания за последние пять лет, то в 2013 г. таких насчитывалось уже 49\%. Одновременно увеличилась и доля тех, кто видит ее улучшение (с 10\% в 2009 г. до 19\% в 2013 г.) (там же). Опрос ФОМ 2012 г. показывает еще более негативные оценки. Так, ухудшение экологической ситуации в последние годы отметили $62 \%$ россиян, улучшение - $5 \%$, остальные $28 \%$ не увидели изменений. Беспокоит экологическая ситуация в регионе $74 \%$ россиян, не беспокоит - 19\%. Больше всего беспокоят респондентов (открытый вопрос): мусор, грязь, свалки - 23\%; загрязнение водоемов, плохая питьевая вода - 17\%; состояние воздуха, его загрязнение - $13 \%$; вырубка лесов, лесные пожары - 12\%; воздействие промышленных предприятий на окружающую среду 12\%; близость автомагистралей, выхлопные газы - 11\% и др. (Экология: полезные..., 2012: Электронный ресурс). Схожие данные были получены двумя годами ранее в ходе опроса ВЦИОМ 2010 г. Основными проявлениями ухудшения окружающей среды, по мнению россиян, являются: загазованность воздуха - 48\%, загрязнение водоемов - 44\%, ухудшение здоровья людей - 36\%, загрязненная питьевая вода - $31 \%$, антисанитарное состояние территории - 30\%, исчезновение лесов - $26 \%$, изменении климата - 22\%, воздействие вредных химических веществ на продукты - 21\% и др. (Россияне..., 2013: Электронный ресурс). Несколько иная комбинация ответов объясняется видом задаваемых вопросов (в первом случае открытый, а во втором - закрытый, с возможностью выбора несколько вариантов ответа). Перечисление респондентами в открытом вопросе основных категорий, характеризующих экологический кризис, свидетельствует о том, что проблема экологии нашла отражение в сознании некоторой части россиян.

В восприятии экологической проблемы прослеживается значительная региональная дифференциация. Наибольшее внимание ей уделяют жители Москвы и Санкт-Петербурга. Так, 72\% столичных жителей отметили, что для них «очень важна» экология в месте проживания, тогда как в других типах поселения такой ответ дали от 48\% до 61\% опрошенных (Экологическое..., 2006: Электронный ресурс). Здесь опять же 
проявляется связь экономики и экологии, не только в части касающейся проблем, порождаемых особенностью экономики столичных мегаполисов, но и более высоком уровне жизни в них, что определяет более высокие требования к качеству жизни.

Опрос ВЦИОМ 2016 г. показал, что большинство (54\%) москвичей обеспокоены экологической обстановкой в городе (из них крайне обеспокоены 32\%, тогда как не обеспокоены только 14\%) и оценивают ее как неблагоприятную (56\%), противоположного мнения придерживаются 40\%. Восприятие экологической ситуации определяется возрастом респондентов. Наиболее благоприятной она кажется самым младшим и старшим возрастным группам: среди 18-24-летних 45\%, среди 56-60-летних 44\%, 61-70-летних 52\%, тогда как среди 25-34-летних только 33\%, а среди 35-44-летних 36\%. Именно последние две группы дают наиболее негативные оценки экологической ситуации: среди 25-34-летних неблагоприятной ее считают $65 \%$, а среди 35-44-летних 61\%. По мнению большей части (37\%) москвичей, экологическая ситуация в столице хуже, нежели в других городах страны, лучше ее считают $17 \%$, а такой же - 22\% (Окружающая..., 2016: Электронный ресурс). Москвичи не только негативно оценивают экологию города, но и полагают, что она ухудшается. Согласно данным ВЦИОМ 2015 г., 43\% москвичей видят ухудшение экологической ситуации в городе за последние пять лет, противоположного мнения придерживаются 20\% (Москва..., 2015: Электронный ресурс). Изменилась ли действительно экологическая ситуация в столице столь существенно, что это нашло отражение в общественном мнении? Серьезных научных данных, подтверждающих ухудшение экологии именно за последние пять лет, найти не удалось. А объяснить эти цифры можно акцентированием экологии, как основной составляющей качества жизни, на фоне нагнетания СМИ экологической угрозы.

Как же москвичи реагируют на эту угрозу? Столичные жители не только осваивают практики участия в экологических проектах, направленных на сохранение окружающей среды, но и меняют свои потребительские предпочтения, ориентируясь на экологически чистые товары. В обществе потребления экология также становится объектом потребления. Озабоченность москвичей проблемой экологии стала активно использоваться бизнесом для формирования потребительского поведения, сфокусированного на экологичности. Такое поведение приобретает все более отчетливые стратификационные черты, поскольку товары (от недвижимости, автомобилей и всевозможных систем очистки воздуха и воды до экологически чистых продуктов и питьевой воды) и услуги, позиционируемые как экологически чистые, стоят дороже.

Но москвичи, впрочем как и россияне в целом, готовы скорее адаптироваться к ухудшению экологии, приобретая разнообразные товары, обещающие минимизировать вредные воздействия окружающей среды на организм человека, нежели улучшить эту среду, изменив свои привычные повседневные практики. Наибольшее опасение у большинства (60\%) москвичей, как показал опрос ВЦИОМ 2016 г., вызывает загрязнение воздуха транспортом (выхлопами). При этом только у 22\% респондентов в семье нет автомобиля, тогда как у 77\% он есть (пользуются им сами - 48\%, другие члены семьи - 29\%) (Окружающая..., 2016: Электронный ресурс). Здесь мы сталкиваемся с расхождением экологического сознания и поведения. Хотя важность этого поведения хорошо известна россиянам. Большинство (76\%) респондентов, как показал опрос ВЦИОМ 2013 г., понимают необходимость использования общественного и экологических видов транспорта для сохранения окружающей среды (Россияне..., 2013: Электронный ресурс). 
Итак, россияне обеспокоены экологической ситуацией, определяя ее как неблагоприятную, и осознают основные факторы экологической угрозы, понимая, что вред окружающей среде наносят не только промышленные предприятия, но и многие повседневные практики индивидов, как например, использование автомобильного транспорта (там же). Но вытекает ли из этого, что социальное поведение индивидов изменяется? Отнюдь нет. Автопарк страны не только не уменьшается, но и ежегодно увеличивается. Эта тенденция продолжится и в будущем, поскольку автомобиль глубоко связан со статусно-престижными характеристиками, что делает обладание им важной целью большинства современных юношей и девушек. В этом и заключается сложность решения проблемы экологии, которая возлагает большую ответственность на каждого человека по изменению его типичных моделей поведения. Подобные перемены предполагают трансформацию ценностно-нормативных структур, что занимает довольно длительный промежуток времени. Основной вектор экологической политики должен задаваться институтом государственной власти, в том числе и по формированию соответствующего экологического сознания новых поколений. Но ответственность за экологию должны разделить и сами люди, не перекладывая ее на социальные структуры. Проблема экологии может быть решена только в том случае, если каждый человек, осознав свою ответственность за окружающую среду и возложив на себя обязательства по ее сохранению, сформирует экологические практики социального поведения и изменит свой образ жизни.

Пока же россиянам свойственно считать, что их образ жизни не наносит окружающей среде ощутимого вреда ((по данным опроса ФОМ 2012 г., так считают 74\% респондентов и только 20\% признают обратное) (Экология: полезные..., 2012: Электронный ресурс)) и возлагать ответственность за состояние экологии в месте своего проживания на кого угодно, только не на самих себя. Так, опрос ВЦИОМ 2010 г. показал, что $27 \%$ респондентов ответственность за окружающую среду возлагают на федеральную власть, правительство в целом, $23 \%$ - на местную власть (городскую, районную), 17\% - на специальные правительственные службы (Минприроды, экологическую полицию, МЧС), $14 \%$ - на региональную власть. И только $12 \%$ считают, что ответственность должны нести сами жители (Россияне..., 2013: Электронный ресурс).

Проблема экологии стала частью публичного дискурса. Обеспокоенность экологической ситуацией в России выражают как высшие органы власти страны, так и население, которое в своих высказываниях демонстрирует понимание нарастающей угрозы. Но реально ли россияне осознают проблемы экологии, или же они, по большей части, носят декларативный характер? Нам представляется, что до полного осознания этой угрозы еще далеко. И вот почему. Особенность проблемы заключается в том, что она носит латентный характер, а ее последствия во многом имеют отсроченный эффект. Проявления экологической проблемы пока не вошли в повседневную жизнь большинства россиян. Именно поэтому эти последствия пока в полной мере ими не ощущаются и в действительности (а не на уровне деклараций) не сильно их беспокоят. В этом и состоит сложность формирования экологического сознания, определяющего соответствующее экологическое поведение, необходимое для обеспечения устойчивого социального развития столицы. К тому же активизация экологического сознания непосредственно затрагивает повседневные практики индивидов, в основе которых лежат ценности, нормы и установки, изменить которые довольно сложно. Однако это вовсе не значит, что ничего нельзя изменить. Экологическую культуру необходи- 
мо формировать, а начать надо с экологического информирования. Аля повышения степени осознания экологической проблемы представляется целесообразным проведение активной кампании по экологическому просвещению населения, акцентируя состояние экологии, последствиях для человека и способах ее улучшения. Осуществление этой задачи предполагает использование потенциала гражданского общества (экологические проекты), привлечение разнообразных информационных средств (кинофильмы, сериалы, социальную рекламу, ток-шоу, реалити-шоу и др.) для воздействия на различные возрастные группы. Особое внимание при проведении пропаганды экологического поведения стоит уделить ресурсу референтных личностей. Но все это не принесет весомого результата без коренного изменения мышления людей, затрагивающего основы современной цивилизации. Новое мировоззрение должно выстраиваться на духовных началах, на гармоничных взаимоотношениях человека с человеком и с природой.

\section{СПИСОК АИТЕРАТУРЫ}

Заседание Государственного совета по вопросу «Об экологическом развитии Российской Федерации в интересах будущих поколений» (2016) [Электронный ресурс] // Официальный сайт Президента России. 27 декабря. URL: http://www.kremlin.ru/events/president/news/53602 [архивировано в WebCite] (дата обращения: 12.01.2017).

Москва - город мечты? (2015) [Электронный ресурс] // ВЦИОМ. Пресс-выпуск № 2921 от 4 сентября. URL: http://wciom.ru/index.php?id=236\&uid=115378 [архивировано в WebCite] (дата обращения: 12.01.2017).

Окружающая среда Москвы: к экологичности через модернизацию (2016) [Электронный ресурс]// ВЦИОМ. Пресс-выпуск № 3178 от 18 августа. URL: http://wciom.ru/index.php?id=236\& uid=115819 [архивировано в WebCite] (дата обращения: 12.01.2017).

Россияне о состоянии окружающей среды (2013) [Электронный ресурс] // ВЦИОМ. Экспертный совет. URL: https://wciom.ru/fileadmin/file/reports_conferences/2013/2013-06-17-ekologiya.pdf [архивировано в WebCite] (дата обращения: 12.01.2017).

Экологическое сознание россиян (2006) [Электронный ресурс]// ВЦИОМ. Аналитика экспертов ВЦИОМ. 7 декабря. URL: http://wciom.ru/index.php?id=238\&uid=3702 [архивировано в WebCite] (дата обращения: 12.01.2017).

Экология: полезные привычки. Россияне - о природе и экологическом поведении (2012) [Электронный ресурс] // ФОМ. 28 мая. URL: http://fom.ru/Obraz-zhizni/10450 [архивировано в WebCite] (дата обращения: 12.01.2017).

\section{REFERENCES}

Zasedanie Gosudarstvennogo soveta po voprosu «Ob ehkologicheskom razvitii Rossijskoj Federacii v interesah budushchih pokolenij» (2016). Oficial'nyj sajt Prezidenta Rossii. 27 dekabrya [online] Avaible at: http://www.kremlin.ru/events/president/news/53602 [arhivirovano v WebCite] (access date: 12.01.2017). (In Russ.)

Moskva - gorod mechty? (2015). VCIOM. Press-vypusk. No. 2921 ot 4 sentyabrya [online] Avaible at: http://wciom.ru/index.php?id=236\&uid=115378 [arhivirovano v WebCite] (access date: 12.01.2017). (In Russ.)

Okruzhayushchaya sreda Moskvy: k ehkologichnosti cherez modernizaciyu (2016). VCIOM. Press-vypusk. No. 3178 ot 18 avgusta [online] Avaible at: http://wciom.ru/index.php?id= 236\& uid=115819 [arhivirovano v WebCite] (access date: 12.01.2017). (In Russ.)

Rossiyane o sostoyanii okruzhayushchej sredy (2013). VCIOM. Ebkspertnyj sovet [online] Avaible at: https://wciom.ru/fileadmin/file/reports_conferences/2013/2013-06-17-ekologiya.pdf [arhivirovano $v$ WebCite] (access date: 12.04.2017). (In Russ.) 
Ehkologicheskoe soznanie rossiyan (2006). VCIOM. Analitika ebkspertov VCIOM. 7 dekabrya [online] Avaible at: http://wciom.ru/index.php?id=238\&uid=3702 [arhivirovano v WebCite] (access date: 12.01.2017). (In Russ.)

Ehkologiya: poleznye privychki. Rossiyane - o prirode i ehkologicheskom povedenii (2012). FOM. 28 maya [online] Avaible at: http://fom.ru/Obraz-zhizni/10450 [arhivirovano v WebCite] (access date: 12.01.2017). (In Russ.)

Аата поступления: 10.01.2017 2.

Тихомиров Амитрий Андреевич - кандидат социологических наук, доцент кафедры политологии и социологии РЭУ им. Г. В. Плеханова. Адрес: 117997, Москва, Стремянный пер., 28, корп. 1. Тел.: +7 (495)958-23-27. E-mail: dat1983@yandex.ru

Tikhomirov Dmitry Andreevich, Candidate of Sociology, Associate Professor, Department of Political Science and Sociology, Plekhanov Russian University of Economics. Postal address: 28 Stremyannaya lane, Building 1, Moscow, Russian Federation, 117997. Tel.: +7 (495) 958-23-27. E-mail: dat1983@yandex.ru

Кисткина Ирина Александровна - студент 4 курса кафедры политологии и социологии РЭУ им. Г. В. Плеханова. Адрес: 117997, Москва, Стремянный пер., 28, корп. 1. Тел.: +7 (495) 958-23-27. E-mail: kistkina95@gmail.com

Kistkina Irina Aleksandrovna, 4th year student, Department of Political Science and Sociology, Plekhanov Russian University of Economics. Postal address: 28 Stremyannaya lane, Building 1, Moscow, Russian Federation, 117997. Tel.: +7 (495) 958-23-27. E-mail: kistkina95@gmail.com

\section{Аля иитирования:}

Тихомиров А. А., Кискина И. А. Проблема осознания экологической угрозы в России [Электронный ресурс] // Горизонты гуманитарного знания. 2017. №2. URL: http://journals.mosgu. ru/ggz/article/view/462 (дата обращения: дА.мм.гггг.). DOI: 10.17805/ggz.2017.2.5 